\title{
Intracellular Detection of Albumin in the Ovaries of Golden Hamsters by Light and Electron Microscopy
}

\author{
Amitabh Krishna* and Katharina SPANEL-Borowski \\ Institut für Anatomie der Medizinischen Universität zu Lübeck, Lübeck, Federal Republic of Germany
}

Received February 27, 1989

\begin{abstract}
Summary. Ovaries were obtained from golden hamsters during proestrus and immersion-fixed for the immunocytochemical localization of albumin by the peroxidase-antiperoxidase method. Another group of ovaries were obtained from immature perfusion-fixed animals which had been stimulated for 48 or $96 \mathrm{~h}$ by gonadotrophins. Perfusion-fixed tissues were processed for the ultrastructural albumin localization using the protein A-gold technique. At the light microscopical level, albumin positive cells were seen more often in the corona radiata and the inner layer of the granulosa, but seldom in the outer layer. Thecal and interstitial gland cells revealed albumin reactivity as did the intra- and extravascular spaces. Using the electron microscope, enriched gold grains signalizing a positive albumin response were detected over lipid droplets of granulosal, thecal and luteal cells. Though labeled coated vesicles were absent, the following functional significance is proposed for this study: precursors of steroidogenesis or steroids may be transferred as ligands of albumin into or within the cell after a receptor-mediated uptake of the albumin ligand complex.
\end{abstract}

Albumin is found in granulosa cells of rats as has been recently demonstrated by immunocytochemistry (SPANEL-BOROWSKI, 1987). The more mature a follicle becomes, the higher the number of positively stained granulosa cells it contains. These are mostly seen in the cumulus oophorus and the portion of the mural granulosa closest to the antrum. Since albumin serves as a protein to carry a variety of substances in the plasma, e.g., steroids or lipids (WESTPHAL, 1970; ROSENOER et al., 1977; SIITERI et al., 1982), the observed presence of albumin in granulosa cells may correspond to a comparable function at the cellular level.
Support for such a hypothesis comes from reports on a possible binding of albumin and its ligands to specific cell membrane receptors of various tissues. This binding triggers the endocytosis of the hormone receptor complex either with or without the internalization of albumin (SZEGO, 1975; SIITERI et al., 1982; OCKNER et al., 1983). Apart from bringing ligands into specific cells, albumin may also remove its ligands from cells or modify their composition through the exchange of substances. Such a process has been discussed concerning the capacitation of murine sperms becoming depleted of sterols and enriched in phospholipids in the presence of albumin (Go and WOLF, 1985).

Due to the possible functions of albumin in the ovary, the particular focus of this study has been to localize albumin at the light and electron microscopical levels in detail. In contrast to the preceding investigation carried out in rats (SPANEL-BOROWSKI, 1987) this study has been conducted in golden hamsters to verify the albumin appearence in the ovaries of a species in which ovarian functions have been extensively studied (SPANEL-BOROWSKI and HeISS, 1986).

\section{MATERIALS AND METHODS}

Laboratory-reared golden hamsters (strain C-lac) were maintained in clear plastic cages with free access to food and water. Room temperature and light (14 h light: $10 \mathrm{~h}$ dark) were automatically controlled. For light microscopical study, 5 adult hamsters were examined for at least 3 regular estrous cycles determined by the appearance of a

\footnotetext{
*Recipient of an Alexander von Humboldt fellowship; A. K.'s permanent address: Department of Zoology, Banaras Hindu Universtity, Varanasi-221005, India
} 
white and creamy discharge from the vagina at estrus (HOFFMAN, 1968). The animals were killed by cervical dislocation on the morning of proestrus. Both ovaries were immediately removed, fixed in Bouin's solution, and embedded in paraffin wax according to commonly used histological techniques.

For electron microscopical study, 29-day-old immature hamsters were subcutaneously stimulated by 50 IU pregnant mare's serum gonadotrophin (PMSG, Sigma, Deisenhofen, FRG) at time ' 0 ', and superovulations were induced by subcutaneous injections of 25 IU human chorionic gonadotrophin (hCG, Primogonyl ${ }^{\mathrm{R}}$, Schering, Berlin, FRG) $60 \mathrm{~h}$ later (SPANELBOROWSKI and HEISS, 1986). This procedure yielded a high number of either antral follicles or secretory corpora lutea when the animals were killed by perfusion fixation 48 or $96 \mathrm{~h}$ after PMSG stimulation, respectively. One hundred IU heparin (Liquemin $100^{\mathrm{R}}$, Hoffmann-La Roche, Grenzach-Wyhlen, FRG) per $100 \mathrm{~g}$ body weight were intraperitoneally injected under anesthesia ( $6 \mathrm{mg}$ pentobarbital/ $100 \mathrm{~g}$ body weight) 15 min before begining the perfusion. The thoracic and abdominal cavities were opened along the body's midline, and a blunt cannula fitted to a silicone tube was introduced into the left ventricle and slowly pushed into the ascending aorta. After fixing the cannula with one clamp, and interrupting the large cervical blood vessels with other clamps, the remaining blood circulation was rinsed by $100 \mathrm{ml}$ Ringer's solution by use of a perfusor, type $\mathrm{V}$ (Braun-Melsungen, Melsungen, FRG). The speed of the perfusor was adjusted to $300 \mathrm{ml} / \mathrm{h}$. After rinsing, $100 \mathrm{ml}$ fixative was injected. The fixative consisted of $1 \%$ glutaraldehyde- $1 \%$ paraformaldehyde- 0.1 M Sörensen's buffer $(\mathrm{pH}$ 7.4). Both ovaries, and for positive or negative controls, the adrenal glands and the adipose tissue surrounding the uterus horn were removed and fixed for another $2-3 \mathrm{~h}$ at $4^{\circ} \mathrm{C}$. Four hundred $\mu \mathrm{m}$ thick sections were cut using a vibratome (Lancer, St. Louis, MO, USA) and portions were selected with the help of a stereomicroscope. Trimmed pieces of tissues were postfixed in $2 \%$ osmium tetroxide in $0.1 \mathrm{M}$ Sörensen's buffer and 3\% sucrose. After dehydration by a graded series of ethanol and polypropylenoxide, the tissues were embedded in Araldite (Merck, Darmstadt, FRG). Semithin sections were cut on a Reichert ultramicrotome OmU3, stained with Richardson's stain, and screened for the appearance of antral follicles with their corona radiata. Ultrathin sections were mounted on $150 \mu \mathrm{m}$ mesh nickel grids coated with formvar.

Immunocytochemistry was performed as given with the exception of minor changes (SPANEL-
BROWSKI, 1987): 1) The deparaffinized sections were treated with $3 \% \mathrm{H}_{2} \mathrm{O}_{2}$ in $10 \%$ methanol for 5 min at the onset of the procedure; 2 ) the first antibody (diluted 1:20,000) corresponded to the one used for ultrastructural antigen localization (see below); and 3) for controls, this antiserum was preadsorbed by hamster albumin (Sigma, Deisenhofen, FRG).

For electron microscopical antigen localization by the protein A-gold method (ROTH et al., 1978; BENDAYAN and ZOLLINGER, 1983), colloidal gold with a diameter of $15 \mathrm{~nm}$ was prepared according to FRENS (1973). Ultrathin sections attached to the grids were floated upside down on drops placed in a moist chamber usually at room temperature. The buffer used was ordinary phosphate buffer to which $0.05 \mathrm{M}$ Tris- $\mathrm{HCl}, 0.9 \% \mathrm{NaCl}, 0.25 \%$ Triton X-100 (Fluka, Buchs, Switzerland), and $0.02 \% \mathrm{NaN}_{3}$ had been added. The sequence of the steps was as follows: 1 ) rinsing in water, $5 \mathrm{~min}$; 2) etching in a saturated aqueous solution of sodium metaperiodate, $60 \mathrm{~min}$; 3 ) rinsing in buffer, $2 \times 5 \mathrm{~min}$; 4) incubation in normal swine serum diluted to $2 \%$ in buffer, $30 \mathrm{~min}$; 5 ) transfer to antiserum (rabbit-antihamster albumin (No. 0108-0342; Dynatech, Denkendorf, FRG) diluted 1: 1,000 with buffer and incubation over night at $4^{\circ} \mathrm{C}$; 6) rinsing in buffer, $2 \times 5 \mathrm{~min}$; 7) incubation in the protein A-gold solution, $60 \mathrm{~min}$; 8) rinsing in buffer, $2 \times 5 \min$; 9) rinsing in water, $2 \times 5 \mathrm{~min}$; 10 ) drying and contrasting with uranyl acetate and lead citrate; and 11) examination in an electron microscope (Philips EM 400).

Three types of controls were performed: 1) the use of antiserum adsorbed with hamster albumin as reported (SPANEL-BOROWSKI, 1987); 2) incubation with protein A-gold solution alone; and 3) incubation with non-labeled protein $A(0.1 \mathrm{mg} / \mathrm{ml})$ between the antibody and the protein A-gold incubation step.

\section{RESULTS}

Under the light microscope, positively stained granulosa cells were visible (Figs. 1-4). The albumin reactivity was attributed to granule-like structures in the cytoplasm. The number of reacting granulosa cells increased with the stage of follicular maturation. Antral follicles preferentially displayed albumin reactive cells in the corona radiata and in the portion of the granulosa closest to the antrum, but less often in the area adjacent to the basal lamina. The zona pellucida of the most intact or regressing follicle types demonstrated a positive response. The follicular fluid responded in a grain-like manner. Moder- 
ate albumin positive deposits were noticed in the intercellular spaces of the granulosa. Some thecal cells as well as interstitial gland cells were assessed as positive by the granule-like appearance of their cytoplasm. There was a striking albumin dependent perivascular reaction all over the cortical stroma and in the medulla. All controls remained negative.
Using the electron microscope, the protein A-gold complex had noticeably accumulated over the lipid droplets of granulosa cells (Figs. 5, 6), signalizing the presence of albumin. Gold particles were also evident over the dense chromatin of granulosa cells, though this response was less than the grain density over the lipid droplets. Enriched gold particles were absent in
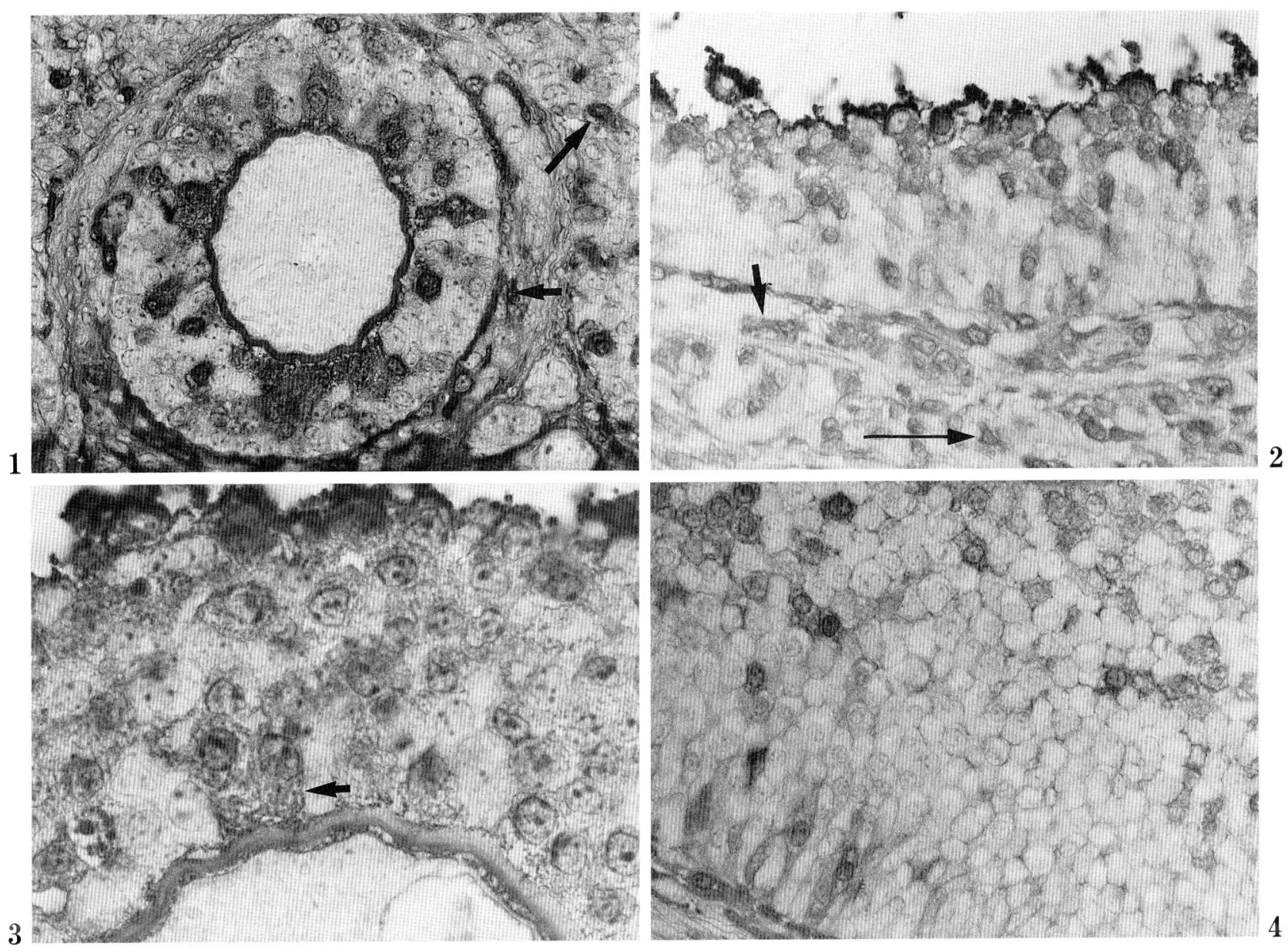

Figs. 1-4. Immunocytochemical localization of albumin by the peroxidase-antiperoxidase method in ovaries of golden hamsters killed during proestrus.

Fig. 1. Albumin positive cells appear in the granulosa of the small-sized preantral follicle, in the theca (small arrow), and in the cortical stroma (large arrow). The zona pellucida shows the presence of albumin. Counterstained with hematoxylin. $\times 220$

Fig. 2. More albumin positive cells are seen in the inner layer of the granulosa of an antral follicle than in the outer layer. Albumin positive fluid is precipitated by fixation on the granulosa layer adjacent to the antrum. Some thecal cells (small arrow) and some cortical cells (large arrow) respond positively. Counterstained with hematoxylin. $\times 220$

Fig. 3. The corona radiata of an antral follicle is rich in albumin positive cells which have a granule-like appearance (arrow). Counterstained with hematoxylin. $\times 430$

Fig. 4. Apart from a certain amount of granulosa cells positively stained for albumin, the intercellular space of the granulosa layer is made apparent by its discrete albumin response. No counterstaining. $\times 220$ 


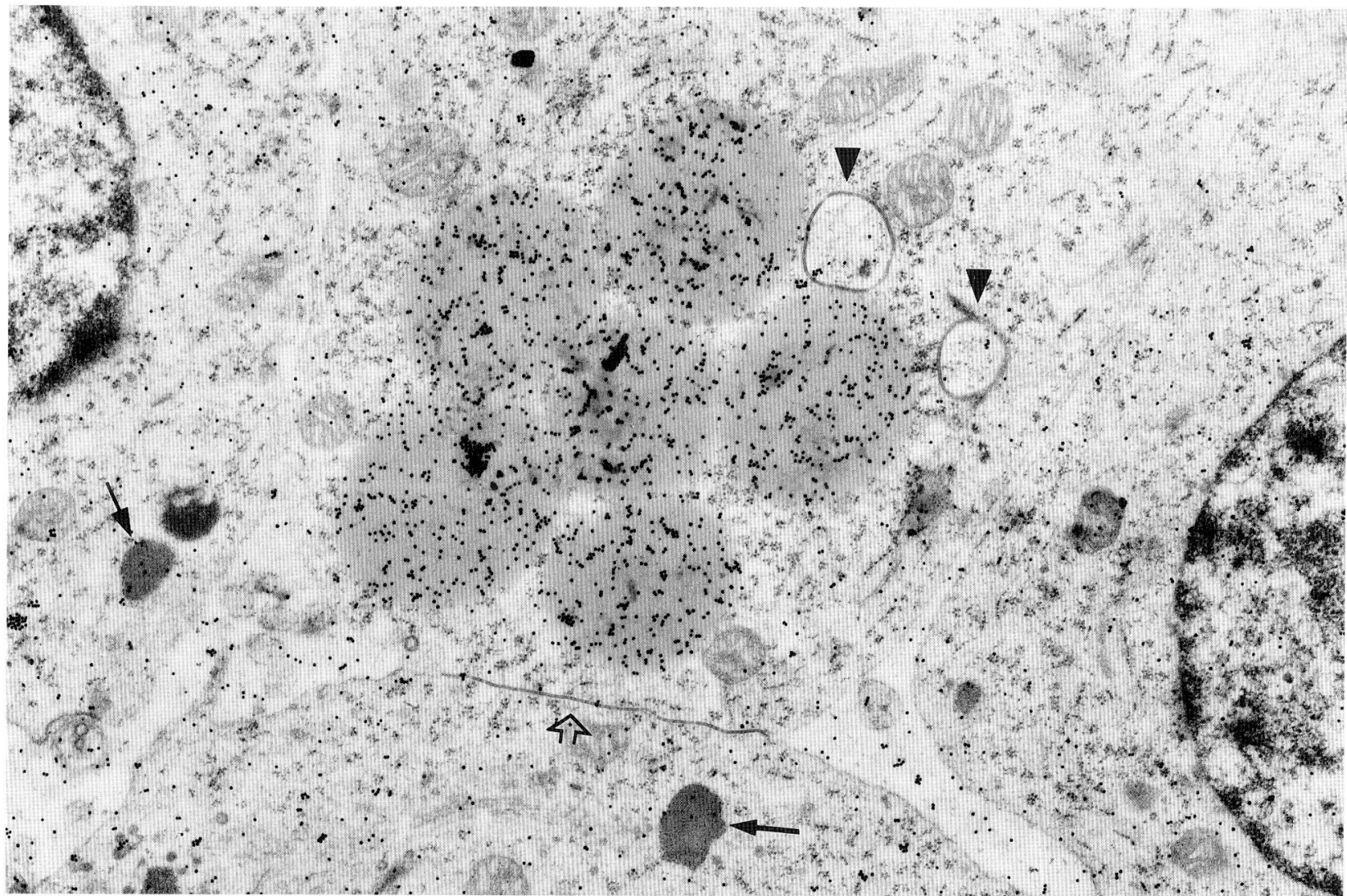

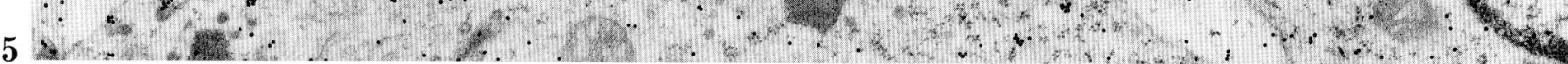

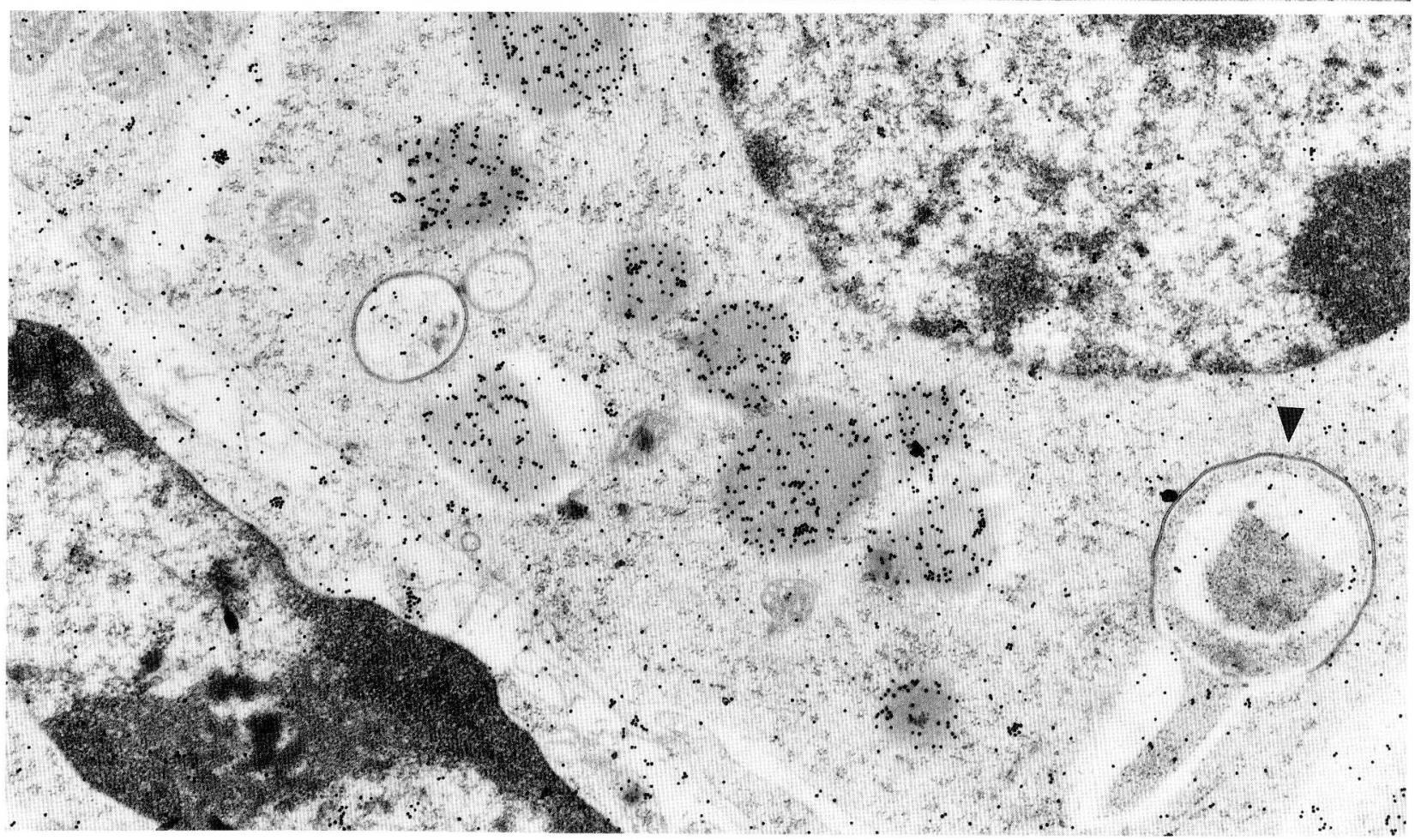

Figs. 5 and 6. Legends on the opposite page. 
secondary lysosomes or other areas of the cytoplasm. Specifically labeled coated vesicles were not noticed. Compared to the background grain distribution, gold grains were only moderately spread over the zona pellucida, on the intercellular spaces of the granulosa, and on the area of the follicular fluid. While controls never revealed enriched particles on lipid droplets or on the intercellular spaces, the dense chromatin did so, indicating an unspecific labeling of the chromatin.

The pattern of gold grains as seen over lipid droplets and over the dense chromatin was confirmed for thecal cells, and for interstitial gland cells of the cortical stroma. Luteal cells reacted similarly (Fig. 7), while endothelial cells of the corpora lutea demonstrated less enriched grains distributed diffusely in the cytoplasm. The extravascular space showed no heavy labeling. This was likely due to the perfusion fixation during which most of the plasma proteins were flushed away. With regard to cells of the adrenal cortex, enriched gold particles were apparent over lipid droplets and over the dense chromatin. The unilocular adipose tissue failed to react. The controls remained negative, with the dense chromatin except. ed.

\section{DISUSSION}

Formaldehyde-fixed tissues are known to be depleted of lipids after dehydration and embedding (HAYAT, 1981). However, tissues fixed by Bouin's solution appear to retain lipids to some extent as seen in our light microscopical results. They reveal granule-like structures in granulosa cells, and in thecal and inter-

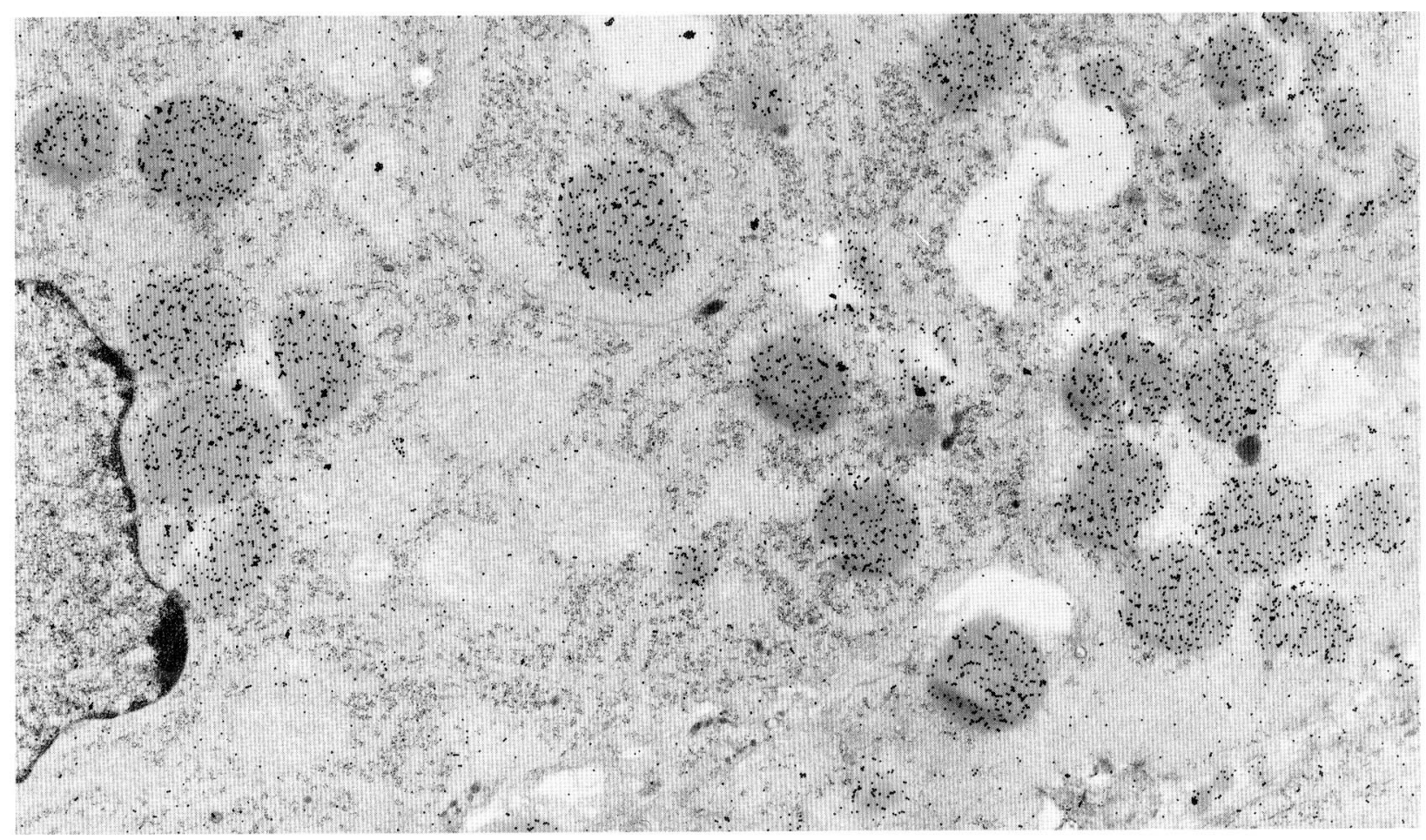

Fig. 7. Many gold grains are shown over intact lipid droplets of luteal cells. Other data are comparable to Figure 5. $\times 12,000$

Fig. 5. Gold particles are striking over lipid droplets of a granulosa cell close to the antrum. Secondary lysosomes lack accumulated grains (arrows). One gap junction (open arrow) and two annular junctions (arrow heads) appear in this antral follicle derived from a golden hamster $48 \mathrm{~h}$ after stimulation with pregnant mare's serum gonadotrophin. $\times 20,000$

Fig. 6. The labeling intensity of lipid droplets seen in a cell of the peripheral portion of the granulosa layer is similar to Figure 5. Three annular junctions are demonstrated: one is tangentially cut (arrow head). Other data are comparable to Figure 5. $\times 20,000$ 
stitial gland cells of the golden hamsters. According to the ultrastructural findings, the granule-like structures can be related to intracellular lipid droplets which have been partially stabilized by fixation with osmium tetroxide (HAYAT, 1981). These lipid droplets show an albumin positive reaction by use of the protein A-gold technique recommended by BENDAYAN and ZOLLINGER (1983). The authors applied a strong oxidizing agent for the antigen detection which is usually masked by osmium tetroxide. Since albumin preparations have been found to be contaminated by lipoproteins (BARTHOLOW and GEYER, 1981), the negative outcome of the control done with preadsorbed antiserum speaks for the specifity of the observed ultrastructural albumin localization and excludes the presence of contaminating antibodies (SPANELBOROWSKI and SCHLEGEL, 1988). Due to the applied fixation and embedding procedure no consistent retention of lipid droplets can be obtained. For this reason, a distribution analysis of the gold labeling will not give concise values.

When MANCINI et al. (1962) intravenously injected labeled serum albumin into rats, the protein was detected by immunocytochemistry and autoradiography in the extravascular space of the entire ovary, in the intercellular spaces of the granulosa layer, and in the antrum. These findings indicated that the follicular wall was permeable to plasma proteins, thus contributing to the composition of the follicular fluid (SHALGI et al., 1977). Therefore, the albumin detected in granulosa cells of golden hamsters may be derived from the plasma, as is the case for the other types of steroid-producing cells studied. More albumin positive cells are visualized close to the oocyte and the antrum than to the outer granulosa layer. Since the distribution of immunoreactive granulosa cells appears to be comparable to given data on growing and regressing follicles of rats (SPANEL-BOROWSKI, 1987), a similar quantification has been omitted in the present study.

The uneven distribution of albumin positive cells in the granulosa layer, herewith confirmed for the golden hamster, allows us to speculate about a receptormediated uptake of albumin. The failure to demonstrate specifically labeled coated vesicles can be explained by the low number of activated and unoccupied receptors whereby specific labeling or background labeling are not distinguished. Nevertheless, our observation allows for speculation on a specific receptor-mediated uptake in accordance with the growing body of evidence about the existence of albumin receptors. Specific albumin binding sites have been demonstrated for the surface of liver or heart cells (OCKNER et al., 1983; HÜTTER et al., 1984) as well as for cells of the capillary endothelium studied in vivo (GHITESCU et al., 1986; SCHNITZER et al., 1988). The possibility exists that receptor-bound albumin participates in the intracellular uptake of a variety of albumin ligands, e.g., fatty acids or hormones. Such a process can take place in addition to other steroid-binding proteins which are known to exist (WESTPHAL, 1970).

If the above is true, then the subcellular appearance of albumin observed in lipid droplets can be dependent on the steroid-producing activity of the cells investigated as well as on their steroid response. Albumin, a lipid soluble protein (ROSENOER et al., 1977), transfers free fatty acids through the plasma membrane to the lipid droplets of steroid-producing cells. Furthermore, albumin may also modulate the lipid level during steroidogenesis comparable to the bidirectional flux of lipids during the acrosomal reaction when albumin accepts cholesterol from sperm cells and supplies them with phospholipids (DAvis et al., 1979; Go and WOLF, 1985). How albumin may act as mediator in steroid-responding cells is unclear at the moment as this study failed to localize albumin in lysosomes. Thus, the assumption of internalized receptorsteroid complexes being processed to cytosol receptors by lysosomal handling cannot be supported (SZEGO, 1975; SIITERI et al., 1982). According to STUMPF $(1983,1984)$, autoradiographic observations have always indicated the presence of nuclear, receptors, while cytosol receptors of steroids have not been seen. In summary, our findings present evidence that albumin may mediate functions of steroid-producing and steroid-responding cells.

Acknowledgments. We thank Prof. Dr. W. KUnHNEL for continuous support and advice, Mr. H. RODE for typing the manuscript, and the Deutsche Forschungsgemeinschaft for their financial help (Sp 232/2-3).

\section{REFERENCES}

Bartholow, L. C. and R. P. Geyer: Sterol release in mammalian cells. The role of a liposomal-free albumin-phospholipid complex. Biochim. Biophys. Acta 665: 40-47 (1981).

Bendayan, M. and M. Zollinger: Ultrastructural localization of antigenic sites on osmium-fixed tissues applying the protein A-gold technique. J. Histochem. Cytochem. 31: 101-109 (1983).

Davis, B. K., R. Byrne and B. Hungund: Studies on the mechanism of capacitation. II. Evidence for lipid transfer between plasma membrane of rat sperm albumin 
during capacitation in vitro. Biochim. Biophys. Acta 558 257-266 (1979).

Frens, G.: Controlled nucleation for the regulation of particle size in monodisperse gold solutions. Nature Phys. Sci. 241: 20-22 (1973).

Ghitescu, L., A. Fixman, M. Simionscu and N. SimioNESCU: Specific binding sites for albumin restricted to plasmalemmal vesicles of continuous capillary endothelium: receptor-mediated transcytosis. J. Cell Biol. 102: 1304-1311 (1986).

Go, K. J. and D. P. Wolf: Albumin-mediated changes in sperm sterol content during capacitation. Biol. Reprod. 32: 145-153 (1985).

HaYAT, M. A.: Fixation for electron microscopy. Academic Press, New York-London, 1981.

Hoffman, R. A.: The golden hamster, its biology and use in medical research. Iowa State University Press, Ames, Iowa, 1968.

Hütter, J. F., H. M. Piper and P. G. SPIEckermann: Myocardial fatty acid oxidation; evidence for an albumin-receptor-mediated membrane transfer of fatty acids. Bas. Res. Cardiol. 79: 274-282 (1984).

Mancini, R. E., O. VilaR, J. J. HeinRich, O. W. Davidson and B. Alvarez: Transference of circulating labeled serum proteins to the follicle of the rat ovary. J. Histochem. Cytochem. 11: 80-88 (1962).

OCKNER, R. K., R. A. Weisiger and J. L. GollaN : Hepatic uptake of albumin-bound substances: albumin receptor concept. Amer. J. Physiol. 245: G13-18 (1983).

Rosenoer, V. M., M. Orata and M. A. Rothschild: Albumin structure, function and uses. Pergamon Press, New York, 1977.

Roth, J., M. Bendayan and L. ORCi: Ultrastructural localization of intracellular antigens by use of protein A-gold comlex. J. Histochem. Cytochem. 26: 1074-1081 (1978).

Schnitzer, J. E., W. W. Carley and G. E. Palade: Specific albumin binding to microvascular endothelium in culture. Amer. J. Physiol. 254: H425-437 (1988).

Shalgi, R., R. Kaplan and P. F. KRaicer: Proteins of follicular, bursal and ampullar fluids of rats. Biol. Reprod. 17: 333-338 (1977).
Silteri, P. K., J. T. Murai, G. L. Hammond, J. A. Nisker, W. J. RAYmoure and R. W. Kulin: The serum transport of steroid hormones. Rec. Progr. Horm. Res. 38: 457-510 (1982).

SPANEL-Borowski, K.: Immunocytochemical localization of albumin in ovarian follicles of fertile rats. Cell Tiss. Res. 248: 699-702 (1987).

Spanel-Borowski, K. and Ch. Heiss: Luteolysis and thrombus formation in ovaries of superstimulated golden hamsters. Aust. J. Biol. Sci. 39: 407-416 (1986).

Spanel-Borowski, K. and W. Schlegel: Pitfall in immunocytochemical localization of prostaglandin $E_{2}$ and prostaglandin $\mathrm{F}_{2} \alpha$ in ovaries of adult rats. Acta Histochem. 83: 121-124 (1988).

STUmpF, W. E.: The histochemistry of steroid hormone receptors. J. Histochem. Cytochem. 31: 113-114 (1983).

- Histochemical characteristics and significance of cell receptors in biology and pathology. Acta Histochem., Suppl. 29: 23-33 (1984).

Szego, M. C.: Lysosomal function in nucleoplasmic communication. In: (ed. by) J. T. DINGLE and R. T. DEAN: Lysosomes in biology and pathology, Vol 4. American Elsevier Publishers, New York, 1975 (p. 385-477).

WESTPHAL, U.: Corticosteroid-binding globulin and other steroid hormone carriers in the blood stream. J. Reprod. Fertil., Suppl. 10: 15-38 (1970).

Dr. Katharina SPANEL-BOROwSKI Institut für Anatomie der Medizinischen Universität zu Lübeck Ratzeburger Allee 160 D-2400 Lübeck Federal Republic of Germany 